\title{
SYNLETT Spotlight 218 \\ tert-Butyl Hydroperoxide (TBHP): A Versatile Oxidizing Agent in Organic Synthesis
}

This feature focuses on a reagent chosen by a postgraduate,

Compiled by Yao Feng Li highlighting the uses and preparation of the reagent in current research

\section{YaoFeng Li was born in Xingtai, Hebei Province (P. R. of China). He received his B.Sc. in chemistry from Hebei Normal University. Presently he is working as a postgraduate at Hebei Normal Univer- sity, under the supervision of Professor Qing-Bin Liu. His research interest focuses on catalytic asymmetric hydrogenation. \\ College of Chemistry \& Material Science, Hebei Normal Universi- ty, Shijiazhuang 050016, P. R. China \\ E-mail: yaofeng2005@163.com}

\section{Introduction}

The clear colorless liquid is widely available as $70-90 \%$ aqueous solutions and anhydrous in hydrocarbon solvents. Aqueous solutions may be dried by a phase-separation procedure, followed by azeotropic distillation to remove the last vestiges of water if necessary. The reagent is used in oxidations of various substrates to give epoxides, ${ }^{1-3}$ ketones, aldehydes, ${ }^{4}$ allylic alcohols,${ }^{5}$ and nitro or imine compounds. ${ }^{6}$ The reagent and its metal complexes have been extensively reviewed. This article describes representative applications to problems in organic synthesis. In view of the lability of the hydroxyl group in tertiary alcohols, it was early suspected that pure hydrogen peroxide in nonaqueous solution would react with tert-butyl alcohol reversibly to form tert-butyl hydroperoxide (TBHP). ${ }^{7}$

\section{Abstracts}

(A) TBHP is widely used as an epoxidizing agent, both synthetically and industrially. TBHP has been used to effect regiospecific, stereospecific, and asymmetric epoxidations. ${ }^{8}$ Zhang and Yamamoto showed that asymmetric epoxidation of allylic alcohols can be carried out using TBHP with a vanadium catalyst and $95 \%$ ee was obtained. ${ }^{9}$

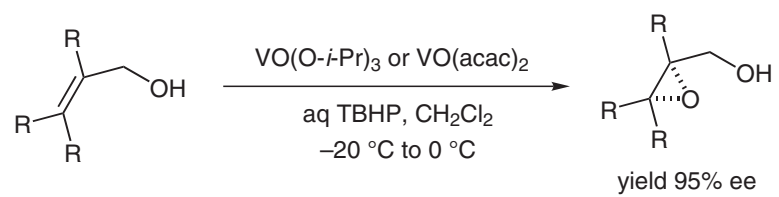

(B) Styrene can be epoxidized by TBHP to styrene oxide with high selectivity and in high yield using barium oxide (with or without gallium oxide support) as a simple, inexpensive and reusable solid catalyst. ${ }^{10}$ trans-Stilbene can be epoxidized by TBHP using a $\mathrm{Au} / \mathrm{TiO}_{2}$ catalyst. $^{11}$

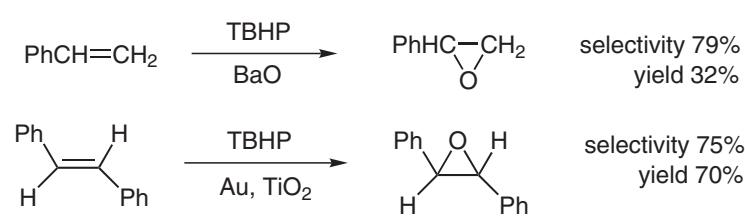

(C) The epoxidation of $\alpha, \beta$-unsaturated ketone and aldehyde compounds is accomplished by TBHP in the presence of catalytic amounts of $\mathrm{Ti}(\mathrm{O} i-\mathrm{Pr})_{4}$ or diaryl-2-pyrrolidinemethanols. ${ }^{12}$ The epoxides have been obtained in good yields and with ee values of $80-90 \% .^{13}$

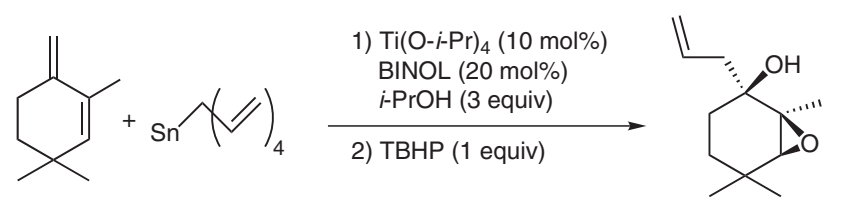

SYNLETT 2007, No. 18, pp 2922-2923

Advanced online publication: 12.10.2007

DOI: 10.1055/s-2007-991086; Art ID: V22307ST

(c) Georg Thieme Verlag Stuttgart · New York 
(D) Manganese(III) acetate catalyzed allylic oxidation of alkenes to the corresponding enones was investigated and showed excellent regioselectivity. ${ }^{14}$ Some new strategies have been reported for a useful transformation of the allylic oxidation of alkenes to carbonyl compounds, such as the protocols using TBHP catalyzed by transition-metal ion centers $(\mathrm{Cr}, \mathrm{Ru}, \mathrm{Cu}, \mathrm{Co}, \mathrm{Pd}) .{ }^{15}$
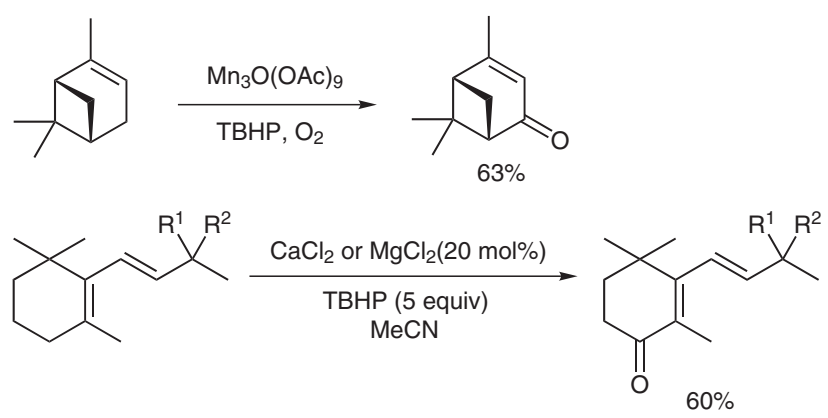

(E) The palladium-catalyzed allylic alkylation (the Trost-Tsuji reaction) is one of the most important reactions for constructing $\mathrm{C}-\mathrm{C}$ bonds in modern organic synthesis. Recently, Chao-Jun Li and co-workers found that when a catalytic amount of $\mathrm{CuBr}$ and a stoichiometric amount of TBHP were used the desired product was obtained in higher yield. ${ }^{16}$

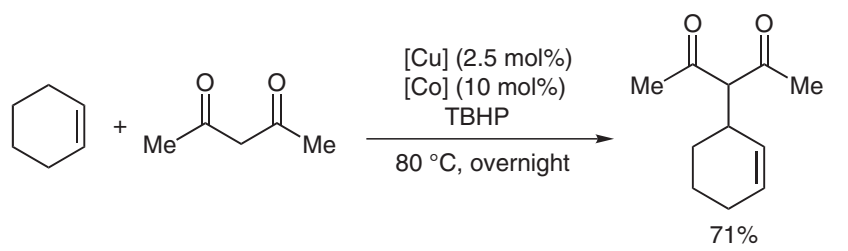

(F) In the presence of a catalytic amount of $\mathrm{CuI}$ and inorganic bases such as $\mathrm{NaHCO}_{3}$, the aldehydes with amine hydrochloride salts gave the amide under mild conditions in good yield. The method can be used as the strategy for amide bond formation. ${ }^{17}$

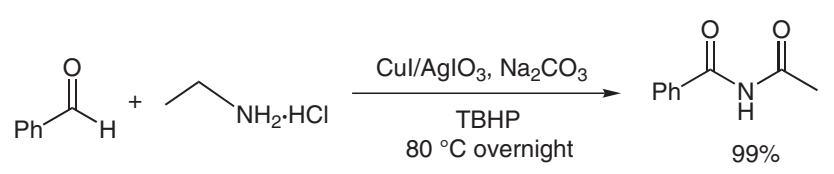

(G) Oxidative cleavage of the $\mathrm{C}=\mathrm{C}$ bond to afford ketone or aldehyde products with TBHP as the oxidant can be catalyzed by AuCl. This oxidation reaction proceeds under mild conditions in water, a variety of functional groups are tolerated. ${ }^{18}$
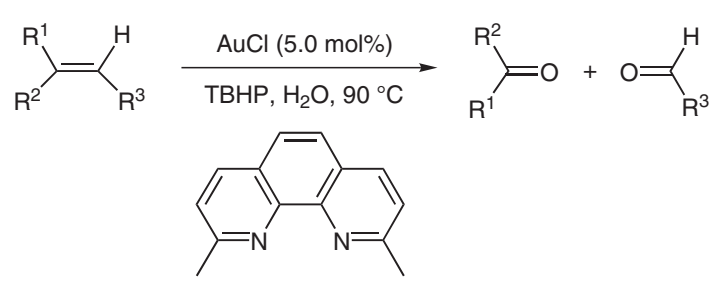

(H) Copper-catalyzed oxidative esterification of aldehydes with $\beta$-dicarbonyl compounds was developed using TBHP as an oxidant. In general, the enol esters were synthesized in good yields (up to $87 \%$ ) and high stereoselectivity under the optimized reaction conditions. ${ }^{19}$

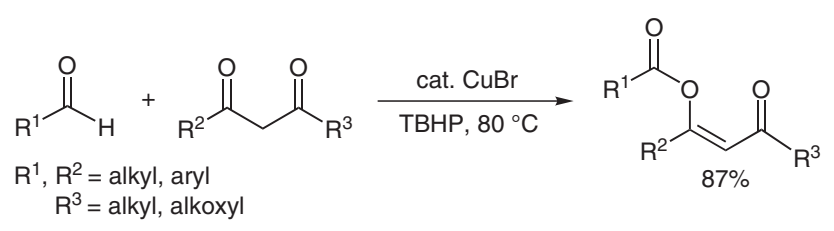

\section{References}

(1) Altinis Kiraz, C. I.; Mora, L.; Jimenez, L. S. Synthesis 2007, 92.

(2) Minatti, A.; Dötz, K. H. Eur. J. Org. Chem. 2006, 268.

(3) Jeon, S. J.; Li, H. M.; Walsh, P. J. J. Am. Chem. Soc. 2005, 127,16416

(4) Cornell, C. N.; Sigman, M. S. J. Am. Chem. Soc. 2005, 127, 2796.

(5) Majumdar, K. C.; Basu, P. K.; Chattopadhyay, S. K. Tetrahedron 2007, 63, 793 .

(6) Yamamoto, K.; Chen, Y. G.; Buono, F. G. Org. Lett. 2005, 7, 4673 .

(7) Milas, N. A.; Harris, S. A. J. Am. Chem. Soc. 1938, 60, 2434.

(8) Lowe, J. T.; Youngsaye, W.; Panek, J. S. J. Org. Chem. 2006, 71, 3639.

(9) Zhang, W.; Yamamoto, H. J. Am. Chem. Soc. 2007, 129, 286.

(10) Choudhary, V. R.; Jha, R.; Jana, P. Green Chem. 2006, 8 , 689.

(11) Lignier, P.; Morfin, F.; Mangematin, L.; Massin, L.; Rousset, J. L.; Caps, V. Chem. Commun. 2007, 186.

(12) Lattanzi, A. Adv. Synth. Catal. 2006, 348, 339.

(13) Wooten, A. J.; Kim, J. G.; Walsh, P. J. Org. Lett. 2007, 9, 381.

(14) Shing, T. K. M.; Yeung, Y.-Y.; Su, P. L. Org. Lett. 2006, 8, 3149.

(15) Yang, M.; Peng, Q. R.; Lan, J. B.; Song, G. F.; Xie, R. G. Synlett 2006, 2617.

(16) Li, Z. P.; Li, C. J. J. Am. Chem. Soc. 2006, 128, 56.

(17) Yoo, W. J.; Li, C. J. J. Am. Chem. Soc. 2006, 128, 13064.

(18) Xing, D.; Guan, B. T.; Cai, G. X.; Fang, Z.; Yang, L. P.; Shi, Z. J. Org. Lett. 2006, 8, 693.

(19) Yoo, W.-J.; Li, C.-J. J. Org. Chem. 2006, 71, 6266. 